\title{
Dynamic coupling law of ecological support capacity and economic social development in Anhui Province from 2000 to 2015
}

\author{
Lifeng Jiao ${ }^{1,2}$, Yalun Gao ${ }^{1}$, Hairu Pan ${ }^{1}$, Guangzhou Chen ${ }^{1, *}$ \\ ${ }^{1}$ School of Environment and Energy Engineering, Anhui Jianzhu University, Hefei 230601, China \\ ${ }^{2}$ Institute of Shanghai Architectural Design \&Research (Co., Ltd.), Shanghai 200041, China
}

\begin{abstract}
By selecting the typical indicators of ecological supporting capability and economic social development to construct the index system, the levels of ecological supporting capability and economic social development in Anhui province from 2000 to 2015 were calculated based on the method of principal component analysis. Then, the scissors difference method was employed to study their dynamic relationship. The results showed that the ecological support ability in Anhui province increased rapidly first and then slowly; and economic social development increased exponentially. Its coupling and coordination degree changed from a serious recession to a well-coordinated development. Through the analysis of the fitting equation and scissors difference, it revealed their interaction law, and provided decision support for the scientific, sustainable development of Anhui province.
\end{abstract}

\section{Introduction}

Eco-civilization is a new form of human civilization. It takes respecting and maintaining nature as its precondition, takes the harmonious coexistence of human beings, nature and society as its purpose, takes establishing sustainable production and consumption modes as its connotation, and guides people to embark on a sustainable and harmonious development path as its focus [1]. In 2004, "Outline of overall planning for the construction of Anhui ecological Province was put into effect. In 2012, "Implementation outline of building a strong ecological province" was carried out.

After years of construction, it was of importance to evaluate the construction effect of ecological province and study the change state of ecological supporting capacity. Furthermore, what is the coupling relationship between ecological supporting capacity and economic social development? This paper attempts to study the above problems.

In terms of research on the ecological carrying capacity, eco-environment and economic development, Nakajima et al. used emergy analysis method and a new ecological footprint algorithm to study the ecological carrying capacity [2]; Kluger et al. used carrying capacity as a tool to manage aquaculture system, and studied the social and economic activities of Sechura Bay [3]. The research on the coupling relationship between systems was as follows: Wang et al. took the western region of Jilin Province as an example to study the dynamic coupling relationship between the ecological support ability and social economic development [4]; Li et al. set up the coupling index model by using emergy analysis, and analysed the present situation of the coupling of the ecological economic system in several provinces in China [5]; Zhang et al. took the Inner Mongolia as the object, and used the coupled model to study its coupling degree between the regional ecological support capacity and socio-economic development during 2001-2010 [6]; Crepin et al. used the dynamic model to study the economic-ecosystem coupling relationship [7].

The existing research results about Anhui province were as follows: Jiang et al. through the use of index system for economic growth and resource environment pressure to quantitatively analyse the resources and environmental pressure faced by Anhui province, and drew a conclusion that the pressure of resources and environment in Anhui had been larger in the past 19992008 [8]. Liu et al. set up the index system of coupling coordination degree for regional economy, tourism and eco-environment; taking Anhui Province as an example, used the mathematical model to analyse their coupling coordination degree from 1990 to 2008 [9]. Gao et al. used the ecological footprint model to study the dynamic changes of ecological footprint of Anhui Province [10]. $\mathrm{Gu}$ et al. employed the coordinated development model and scissors difference method, took the Huainan city as an example to quantitatively analyse the degree of coordination and change trend of ecological footprint and economic development [11].

The above works have achieved some achievements, however there is short of the analysis of long time series aimed at their coupling relationship. In this paper, selecting corresponding data from 2000 to 2015, the principal component analysis and scissors difference

\footnotetext{
* Corresponding author: chgzh5@163.com
} 
theory were used to analyse the coupling evolution patterns between ecological supporting capacity and economic social development in Anhui province based on the coupled equation and fitting model. Further, it was expected to provide a decision-making basis for the future sustainable development of the ecological construction for Anhui Province.

\section{Research Areas and Methods}

\subsection{Overview of the study area}

Anhui Province located in East China, and located in the middle and lower reaches of the Yangtze River and Huai River, and belongs to China's Middle East Economic Zone, the total area is 140100 square kilometres [12].

It is a transitional region between warm temperate zone and subtropical zone in climate. In the north of Huai River, it is a warm temperate semi-humid monsoon climate, and the south belongs to sub-thermal humid monsoon climate. In different regions, precipitation is changing obviously. It is one of the regions with obvious monsoon climate. Hydrology is characterized by strong monsoon climate characteristics. Runoff varies from year to year and its distribution is uneven. In the north, water resource was deficient.

\subsection{Data sources and methods}

According to the typical characteristics of the ecological support ability and economic social development of Anhui Province, we had made reference to the existing results [4], and adjusted some indicators so as to accurately reflect the indicators of the quality of the ecosystem and set up the index system. The data used mainly come from the statistical yearbook of 2001 2016 [13].

\subsubsection{Coupled coordination model}

For the interaction and connection between ecological environment and social economy, a single model is often used to treat the two systems in isolation. In this paper, the coupling coordination model was selected through literature research. Coupling refers to the phenomenon that two or more systems or forms of motion interact with each other through various interactions. The design of coupling evaluation index of eco-economic system should consider two subsystems of eco-environment, economic social development. There are not only indicators of changes in eco-environment factors, but also order parameters indicating economic and social development. They can reflect the efficient synergy between eco-subsystem and economic subsystem. At the same time, when selecting indicators, they should be representative, and positive and negative indicators should be taken into account. This paper examined the coupling state from both positive and negative aspects, and collected indicators according to the two subsystems of ecological environment and economic social development.

The ecological support capacity and the level of economic social development are both non-linear processes that gradually change with time. And their evolution equations can be expressed as follows:

$$
\begin{aligned}
& \mathrm{F}(x)=f\left(x_{1}, x_{2}, \ldots, x_{n}\right) \\
& \mathrm{F}(y)=f\left(\mathrm{y}_{1}, \mathrm{y}_{2}, \ldots, \mathrm{y}_{n}\right)
\end{aligned}
$$

In the formulas, $x$ and $y$ are the elements of ecological support capacity, economic social development system respectively. The coupling relationship between ecological support capacity and economic social development can be modelled as a coordinated development model.

$$
\begin{gathered}
\mathrm{D}(x, y)=\sqrt{\mathrm{C} \times \mathrm{T}} \\
\mathrm{C}=\left[\frac{\mathrm{F}(x) \mathrm{F}(\mathrm{y})}{\left(\frac{\mathrm{F}(\mathrm{x})+\mathrm{F}(\mathrm{y}))^{2}}{2}\right]^{\mathrm{k}}}\right]^{\mathrm{T}}=a F(x)+b F(y)
\end{gathered}
$$

In the formulas: $k$ is the coordination coefficient, it is set to $2 ; C$ is the coordination index of ecological support capacity and economic social system; $\mathrm{T}$ is their comprehensive development index; $a$ and $b$ are the undetermined coefficients, in view of their equally importance to regional development, this paper takes $a=b= \pm 0.5$. Coupled coordination degree $\mathrm{D}(x, y)$ indicates their quantity degree of combination coordination which maximizes the combined benefit (product of $F(x)$ and $F(y)$ ) under the certain general efficiency (sum of $F(x)$ and $F(y)$ ).

\subsubsection{Scissor difference method}

The scissors difference method is a way to reflect the difference between two trends. In this paper, the scissors difference was used to reflect difference of ecological support ability, economic social development at a certain time point, and was expressed by the angle $\alpha$ between the two tangents of the curve at a given time point (t). The greater the value of $\alpha$, the greater the difference between the two curves (change trend).

Their evolution rates are as follows:

$$
\begin{aligned}
& \mathrm{v}(x)=\mathrm{F}^{\prime}(x) \\
& \mathrm{v}(y)=\mathrm{F}^{\prime}(y)
\end{aligned}
$$

The scissors difference between the change rates of the two systems can be calculated as follows:

$$
\begin{aligned}
& \alpha=\arctan \left|\frac{\mathrm{F}^{\prime}(\mathrm{x})-\mathrm{F}^{\prime}(\mathrm{y})}{1-\mathrm{F}^{\prime}(\mathrm{x}) \mathrm{F}^{\prime}(\mathrm{y})}\right| \\
& (0 \leq \alpha<\pi / 2)
\end{aligned}
$$

\subsubsection{Construction of index system}

According to the characteristics of the ecological environment and economic social development of Anhui Province, the evaluation index selected was shown in Table 1. 
Table 1. Evaluation indicators for the ecological supporting capacity and economic social development in Anhui province.

\begin{tabular}{|c|c|c|c|}
\hline Indicator & $\begin{array}{c}\text { Ecological supporting } \\
\text { capacity }\end{array}$ & Indicator & $\begin{array}{c}\text { Socio-economic } \\
\text { development }\end{array}$ \\
\hline $\mathrm{x}_{1} \quad(+)$ & $\begin{array}{l}\text { Per capita arable land } \\
\text { area }\left(\mathrm{hm}^{2}\right)\end{array}$ & $\mathrm{y}_{1} \quad(+)$ & Per capita GDP (yuan) \\
\hline $\mathrm{x}_{2}(+)$ & $\begin{array}{c}\text { Per capita grassland } \\
\text { area }\left(\mathrm{hm}^{2}\right)\end{array}$ & $\mathrm{y}_{2}(+)$ & $\begin{array}{l}\text { Per hectare land GDP } \\
\text { (yuan) }\end{array}$ \\
\hline $\mathrm{x}_{3}(+)$ & $\begin{array}{l}\text { Per capita forest area } \\
\left(\mathrm{hm}^{2}\right)\end{array}$ & $\mathrm{y}_{3} \quad(+)$ & $\begin{array}{c}\text { Per capita production of } \\
\text { grain }(\mathrm{kg})\end{array}$ \\
\hline $\mathrm{x}_{4} \quad(+)$ & $\begin{array}{l}\text { Land Productivity } \\
\qquad\left(\mathrm{kg} \mathrm{hm}^{-2}\right)\end{array}$ & $\mathrm{y}_{4}(+)$ & $\begin{array}{l}\text { Per capita disposable } \\
\text { income of urban and } \\
\text { rural residents(yuan) }\end{array}$ \\
\hline $\mathrm{x}_{5}(+)$ & $\begin{array}{l}\text { Per capita water } \\
\text { resources }\left(\mathrm{m}^{3}\right)\end{array}$ & $\mathrm{y}_{5}(-)$ & $\begin{array}{c}\text { The first industry GDP } \\
\text { ratio(\%) }\end{array}$ \\
\hline $\mathrm{x}_{6} \quad(+)$ & $\begin{array}{l}\text { Per hectare land water } \\
\text { resources }\left(\mathrm{m}^{3}\right)\end{array}$ & $\mathrm{y}_{6} \quad(+)$ & $\begin{array}{l}\text { Per capita net income of } \\
\text { rural household (yuan) }\end{array}$ \\
\hline $\mathrm{x}_{7} \quad(+)$ & Effective irrigation (\%) & y7 (-) & $\begin{array}{c}\text { Chemical fertilizer input } \\
\text { intensity }\left(\mathrm{kg} \mathrm{hm}^{-2}\right)\end{array}$ \\
\hline $\mathrm{x}_{8} \quad(+)$ & Grassland coverage (\%) & $\mathrm{y}_{8} \quad(-)$ & $\begin{array}{l}\text { Growth ratio of } \\
\text { population (\%) }\end{array}$ \\
\hline $\mathrm{x}_{9} \quad(+)$ & Forest coverage $(\%)$ & $\mathrm{y}_{9} \quad(+)$ & Urbanization level(\%) \\
\hline $\mathrm{x}_{10} \quad(-)$ & $\begin{array}{l}\text { Ratio of water and } \\
\text { wetland (\%) }\end{array}$ & $\mathrm{y}_{10}(-)$ & Engel coefficient $(\%)$ \\
\hline \multirow[t]{2}{*}{$\mathrm{x}_{11} \quad(+)$} & $\mathrm{NPP}\left(\mathrm{gC} \mathrm{m} \mathrm{m}^{2}\right)$ & $\mathrm{y}_{11}(+)$ & $\begin{array}{l}\text { Technologists per } \\
10000 \text { persons }\end{array}$ \\
\hline & & $\mathrm{y}_{12}(+)$ & $\begin{array}{l}\text { Per capita housing } \\
\text { area }\left(\mathrm{m}^{2}\right)\end{array}$ \\
\hline
\end{tabular}

\subsection{Data Processing}

SPSS 20.0 software was used to quantify the ecological support capacity, the evolution of economic social development in the study area by principal component analysis. The main steps are: (1) normalization: aimed at the positive index, $\mathrm{x}_{\mathrm{i}}=\left(\mathrm{x}_{\mathrm{i}}-\mathrm{x}_{\text {min }}\right) /\left(\mathrm{x}_{\max }-\mathrm{x}_{\text {min }}\right)$; aimed at the negative index, $x_{i}=\left(x_{\max }-x_{i}\right) /\left(x_{\max }-x_{\min }\right) ;(2)$ calculation of correlation coefficients between sample variables; (3) The eigenvalues, variances and cumulative variance contribution rates of the sample correlation matrix are calculated. The number of principal components is determined according to the principle that the cumulative contribution rate of variance is more than $85 \%$, and the principal component factor load and factor score are obtained.

The first three principal components of $F(x)$ and the first one of $F(y)$ were obtained by principal component analysis (Table 2). Taking the variance contribution rate of each principal component as the weight, using the principal component score value to establish the expression to quantify the ecological support capacity, social economic evolution state equation:

$$
\begin{array}{r}
F(x)=0.4599\left[\mathrm{M}_{1}^{1}, \mathrm{M}_{1}^{2}, \ldots, \mathrm{M}_{1}^{11}\right]\left[X_{1}, X_{2}, \ldots, X_{11}\right]^{T}+ \\
0.22225\left[\mathrm{M}_{2}^{1}, \mathrm{M}_{2}^{2}, \ldots, \mathrm{M}_{2}^{11}\right]\left[X_{1}, X_{2}, \ldots, X_{11}\right]^{T}+
\end{array}
$$$$
0.14501\left[\mathrm{M}_{3}^{1}, \mathrm{M}_{3}^{2}, \ldots, \mathrm{M}_{3}^{11}\right]\left[X_{1}, X_{2}, \ldots, X_{11}\right]^{T}
$$$$
\mathrm{F}(y)=0.90088\left[\mathrm{~N}_{1}^{1}, \mathrm{~N}_{1}^{2}, \ldots, \mathrm{N}_{1}^{12} \llbracket Y_{1}, Y_{2}, \ldots, Y_{12}\right]^{T}
$$

In the formula, $X$ and $Y$ are the $F(x)$ and $F(y)$ standardized index matrices, while $M$ and $N$ are the principal component score coefficient matrices obtained by orthogonal rotation method for the ecological support capacity and social economic development of the study area.

Table 2. Eigenvalue and cumulative contribution of the principal components.

\begin{tabular}{|c|c|c|c|c|}
\hline \multicolumn{2}{|c|}{$\begin{array}{c}\text { Principal } \\
\text { components }\end{array}$} & Eigenvalue & Variance (\%) & $\begin{array}{c}\text { Cumulative } \\
\text { variance (\%) }\end{array}$ \\
\hline $\mathrm{X}$ & $\mathrm{C}_{1}$ & 5.059 & 45.990 & 45.990 \\
\hline & $\mathrm{C}_{2}$ & 2.445 & 22.225 & 68.215 \\
\hline & $\mathrm{C}_{3}$ & 1.595 & 14.501 & 82.717 \\
\hline $\mathrm{Y}$ & $\mathrm{C}_{1}$ & 10.811 & 90.088 & 90.088 \\
\hline
\end{tabular}

\section{Results and analysis}

\subsection{Change trend of ecological support and economic-social development}

According to figure 1 (a), from 2000 to 2015, the ecological support capacity of Anhui province showed an upward trend, which rose from -0.018 in 2000 to 3.189 in 2008. Thereafter, 2008-2014 years showed a fluctuating state, basically maintained at around 3.2, and then increased to 4.588 in 2015 . The main reasons for the increase of $F(x)$ in the study area are as follows: 1) the land productivity increased steadily during the study period, from $0.012 \mathrm{~kg} \mathrm{hm}^{-2}$ in 2000 to $0.025 \mathrm{~kg} \mathrm{hm}^{-2}$ in 2015 ; 2) the net primary productivity (NPP) and the effective irrigation area increased slowly during the study period; 3 ) the cultivated land area decreased during 2000-2004, and from 2005 to 2013 it showed a slow growth trend, then showed rapid growth from 2014 to 2015.

Figure 1 (b) showed that the economic social development had been on the rise from 2000 to $2015,{ }^{F(y)}$ rose from -0.044 in 2000 to 0.78 in 2015 . In terms of economic development, per capita GDP increased from 4623 yuan to 31667 yuan during the study period, and the per capita grain output increased from $3938 \mathrm{~kg}$ to $5091 \mathrm{~kg}$. In terms of social development level, the level of urbanization rose from $28 \%$ to $50.5 \%$, and the Engel coefficient decreased from $45.7 \%$ to $33.7 \%$. In 2015, the number of scientific researchers per 10000 people and per capita living area, were greater than those in 2000 , respectively. 

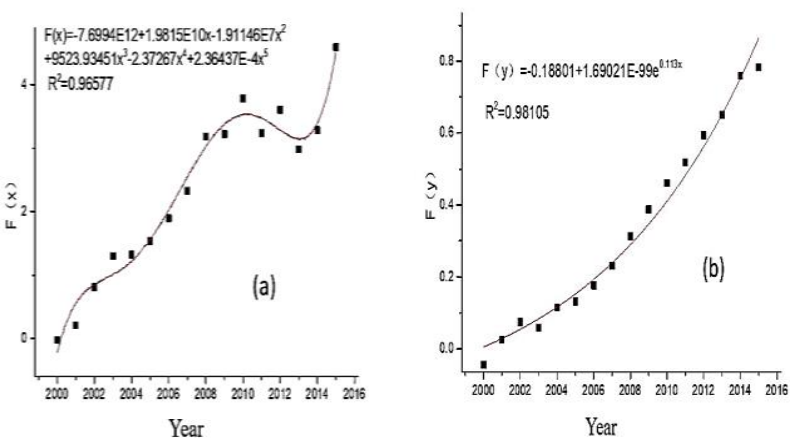

Fig.1. Evolution of the ecological supporting capacity $F(x)$ (a) and economic social development $F(y)$ for Anhui Province (2000-2015) (b)

\subsection{Coupling coordination}

The coupling coordination degree D changed from 0.148 in 2000 to 0.868 in 2014 , and a slight decrease of 0.815 in 2015 (Fig.2 (c)). The results showed that the degree of coordination between the two systems was upward trend on the whole during the study period, and indicated that the two systems were in a relatively coordinated development trend.

Seen from the two factors affecting the coupling degree of coordination (comprehensive development index and coordination index): (1) the comprehensive development degree $\mathrm{T}$ of $F(x)$ and ${ }^{F(y)}$ showed a trend that rose first, then showed some volatility, and then rose (Fig.2(b)). Although there was little difference between 2008 and 2014, the internal combination state changed: the growth rate of $F(x)$ slowed down and that of $F(y)$ continued to rise. It indicated that the ecological support capacity remained basically unchanged, while the economic development showed a relatively rapid growth. (2) The change of the coordination index (C) of $F(x)$ and ${ }^{F(y)}$ could be divided into two sections (Fig. 2 (a)): the decline stage is from 2000 to 2003 , although the coordination index was the highest in 2000 , however the two index are negative value and close to each other, therefore it belonged to the low-level coordination; the $\mathrm{C}$ value rose slowly and remained relatively stable during 2004-2008; the second stage showed an increasing trend from 2008 to 2015, peaking in 2014 and then declining in 2015 .

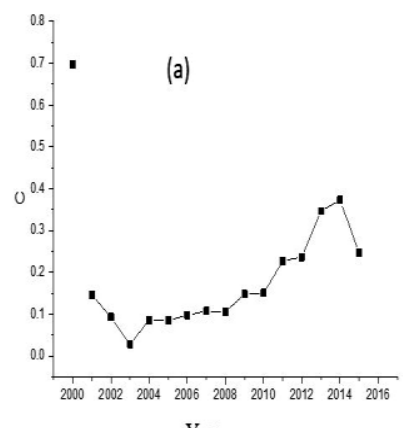

Year

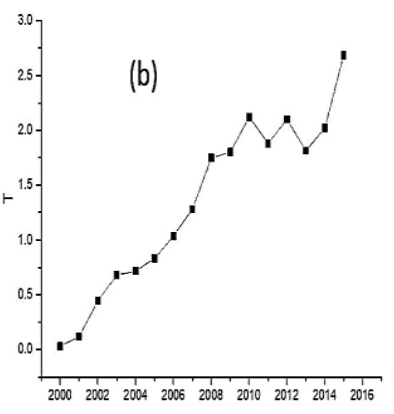

Year

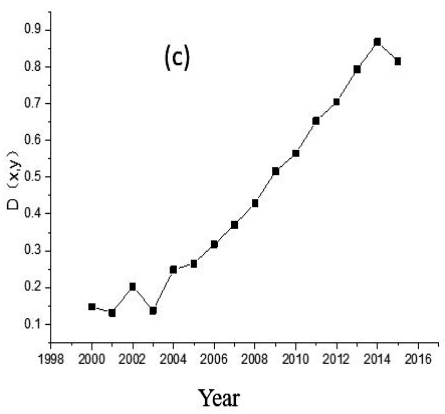

Fig .2. Coupling coordinate degrees $\mathrm{D}(x, y)$, comprehensive development degree $\mathrm{T}$ and harmonious degrees $\mathrm{C}$ for Anhui Province (2000-2015)

The criterion of $D$ is following[4,11]: $0 \sim 0.09$, Extreme inharmonious recession; 0.1 0.19, Serious inharmonious recession; 0.2 0.29, Moderate inharmonious recession; 0.3 0.39, Elementary inharmonious recession; 0.4 0.49, Critical inharmonious recession; 0.5 0.59, Barely harmonious development; 0.6 0.69, Elementary harmonious development; 0.7 0.79, Moderate harmonious development; 0.8 0.89, Favorable harmonious development; 0.9 1.00, Excellent harmonious development.

The coupling coordination degree of Anhui province changed from the severe maladjusted recession type early to the good coordinated development type in 2014. It showed that the research area gradually changed from harming ecosystem carrying capacity to promote social and economic development. However, from the change of $T$ and $C$, there was still a conflict between the comprehensive development index and coordinating index from 2000 to 2015: the coordinating index increased slowly.

\subsection{Scissors difference analysis}

When the curves of the ecological supporting capacity and the level of economic social development in Anhui province were fitted, some information points with relatively large variability were discarded. So, the scissors difference and the change rate obtained represented a general trend of evolution for $^{F(x)}$ and ${ }^{F(y)}$, and there might be some variability in some years. As can be seen from Figure 1, the fluctuation of ${ }^{F(x)}$ was relatively large during 2000-2015, the order of variables of the evolution equation was relatively high, and $F(y)$ showed the exponential growth. Seen from Figure 3, the scissors gap of $F(x)$ and $F(y)$ decreased 
slowly along with the growth of year. It showed that with the development of economy and society, the supporting capacity of ecological environment was relatively good.

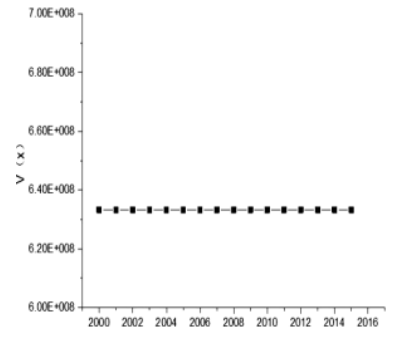

Year

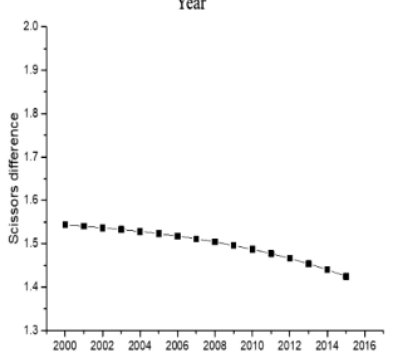

Year

Fig.3. Changing rates of the ecological support capacity V(x) and socio-economic development $\mathrm{V}(\mathrm{y})$, and the scissors difference for Anhui province (2000-2015)

From 2000 to $2008,{ }^{F(x)}$ and ${ }^{F(y)}$ showed an upward trend and changed in the same direction. It showed that the ecological support ability could support the economic and social development (the ecological environment was relatively good). The coupling degree between the two subsystems was maladjusted recession under the backward economic development state. From 2009 to $2015, F(x)$ tended to stable and ${ }^{F(y)}$ further grew, the $\mathrm{T}$ value fluctuated, indicating that the antagonism between social-economic development and ecological supporting capacity in this period was strong. The development of the ecological support capacity of Anhui Province was limited, that was, eco-environment had a larger constraint on the economic social development. However, the $\mathrm{C}$ value increased step by step, indicating that the degree of coordination between the two subsystems increased gradually, and the sustainability was better. Coupled with the slow reduction of the scissors difference $(\alpha)$ of evolution rate for $^{F(x)}$ and ${ }^{F(y)}$, the coupling degree had gradually changed into favorable harmonious development state, indicating that the overall development quality of Anhui Province was relatively good.

\section{Conclusion}

In this paper, the coupling coordination model was used to study the relationship between the ecological support capability and economic social development. Through the analysis of fitting equation and scissors difference, the coupling relationship was determined based on the evolution rate and direction aimed at ${ }^{F(x)}$ and $F(y)$.
The following suggestions were put forward to improve the ecological support capacity of Anhui Province: 1) scientific and rational use of land resources to ensure the preservation of cultivated land and enhance the stability of the land system; 2) the distribution difference of water resources was large in north and south of Anhui province, and the water resources in the north of Anhui Province should be strengthened to protect and enhance the supply capacity of water resources; 3 ) increase the coverage rate of forest land and grassland, and improve the overall forest coverage; 4) readjust the industrial structure, shift to a resourcesaving and environment-friendly industry; (5) actively implement the concept of ecological civilization development, strengthen ecological protection and restoration, and strictly abide by the ecological red line; carry out restoration of damaged ecosystem, improve and enhance ecosystem service function.

\section{Acknowledgements}

This work was financially supported by the Natural Science Project of Education Department of Anhui Province (Grant no. KJ2018A0508); Project of Anhui Jianzhu University (JR182002); Excellent top-notch talents training funding project (2019gxbjZD24); Key Project of Outstanding Young Talents of Universities in Anhui Province (gxyqZD2016148).

\section{References}

1. P. Xie. The natural origin of ecological civilization . Lake science, 28,1(2016)

2. E.S. Nakajima, E. Ortega. Carrying capacity using emergy and a new calculation of the ecological footprint. Ecological Indicators, 60(2016)

3. L. C. Kluger, M. H. Taylor, J. Mendo, J. Tam, M. Wolff. Carrying capacity simulations as a tool for ecosystem-based management of a scallop aquaculture system. Ecological Modelling,331(2016)

4. M.Q. Wang, J.D. Wang, J.S. Liu, K.K. Gu. Dynamic coupling relationship between ecological supporting capacity and social economic development in the west of Jilin Province. Journal of Applied Ecology, 20:170-176 (2009)

5. S. Li. Study on eco-economic system coupling relation and its path in provinces of China. Guangdong Agricultural Science, 19:205-208. (2012)

6. Y.F. Zhang, H.Q. Wang, Y.N. Tian. Coupling Analysis of Ecological Supporting Capability and Socioeconomic Development of Inner Mongolia. Environmental Science and Technology, 37(5):199204(2014)

7. A.S. Crepin, J. Norberg, K.G. Maler. Coupled economic-ecological systems with slow and fast dynamics-Modelling and analysis method. Ecological Economics, 70:1448-1458 (2011)

8. Y.H. Jiang, D.P. Liu. An analysis of the pressure of Anhui economic development on resources and 
environment. China Population Resources and environment, 21:152-157(2011)

9. D.H. Liu, Y.C. Yang. Study on the coupling coordination degree of regional economy-tourismecological environment: a case study of Anhui Province. Resources and environment in the Yangtze Basin, 20:892-896(2011)

10. J. Gao, W.C. Su, J. Xu. Dynamic changes of ecological footprint in Anhui Province under the background of rapid urbanization. Shandong Agricultural Sciences, 47 :75-79 (2015)

11. K.K. Gu, J.L. Chu, X.H. Chen et al. An Evaluation of the Coordination of Eco-Economy System of Coal Mining City-A Case of Huainan City. East China Economic Management, 30:84-87. (2016)

12. Anhui Provincial People's Government. Overview of Anhui. http://www.ah.gov.cn/UserData/ SortHtml /1/20182625626.html.

13. Statistics Bureau of Anhui Province. Statistical yearbook of Anhui Province (2001 2016). Beijing: China Statistics Press. 